\title{
Bone Infection, CTCAE
}

National Cancer Institute

\section{Source}

National Cancer Institute. Bone Infection, CT CAE. NCI Thesaurus. Code C143331.

A disorder characterized by an infectious process involving the bones. 